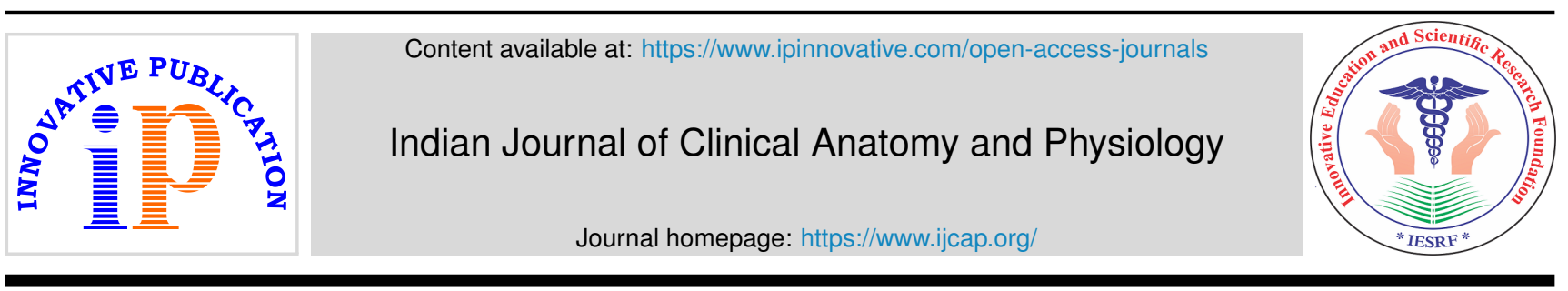

\title{
Editorial
}

\section{The couch potato syndrome: A major concern in Covid 19 pandemic}

\author{
Harpreet Kour ${ }^{1, *}$ \\ ${ }^{1}$ Dept. of Physiology, J.N Medical College, Belagavi, Karnataka, India
}

\section{A R T I C L E I N F O}

Article history:

Received 08-04-2021

Accepted 15-05-2021

Available online 06-07-2021
(C) This is an open access article distributed under the terms of the Creative Commons Attribution License (https://creativecommons.org/licenses/by/4.0/) which permits unrestricted use, distribution, and reproduction in any medium, provided the original author and source are credited.
The Covid-19 Pandemic has affected a massive disruption in the human race across the globe. Most of the population is working from home, hooked with their comfortable couches, prolonged screening time on television and smartphones, less physical activity pushing them unknowingly towards a sedentary lifestyle with deleterious health effects, and eventually leading to Couch Potato Syndrome. A common description of a sedentary person would be someone who spends the majority of the day either sitting or lying down - activities that require an energy expenditure of $1.0-1.5$ basal metabolic rate every day. ${ }^{1-3}$

Sedentary behavior and sitting for long periods have been associated with a number of health concerns viz; obesity, increased blood pressure, high blood sugar, excess body fat around the waist and abnormal cholesterol levels, metabolic syndrome, etc. Prolonged periods of sitting also seem to increase the risk of death from cardiovascular disease, cancer, and stroke with sitting now being called the "new smoking". Studies have shown that sitting for more than six hours a day causes premature death. The proposed mechanisms linking include alterations in muscles' lipid and glucose uptake mechanisms, and also changes in blood vessel functions. A study on African Americans analyzed Health and lifestyle data of 3,592 people over a period of 8.5 years and have reported a $50 \%$ higher risk of cardiovascular problems and premature death in people who are reported

\footnotetext{
* Corresponding author.

E-mail address: harpreet.kour@yahoo.co.in (H. Kour).
}

sitting and watching TV for 4 or more hours each day. However, the same increase in risk did not apply when the hours of sitting took place at work - participants who sat for extended periods in the office did not have a higher cardiovascular risk than those who spent little time sitting at work. ${ }^{2-5}$

Another study looking at 10,185 apparently healthy individuals between the age of 25 and 74-years suggests that out of several type-specific sitting behaviors, only TV sitting showed statistically significant associations with the Framingham score (cardiovascular risk score), independent of confounding variables of age, education, employment status, leisure-time physical activity, BMI, and study year. ${ }^{4,5}$

The problem of a decrease in the level of physical activity with a simultaneous increase in time spent sitting is global and affects people of all ages.

\section{Remedial Measures ${ }^{1-4}$}

1. Daily workouts should be continued even during a pandemic to stay healthy and fit. Ideally, an individual should walk 10,000 steps or five kilometers a day.

2. The recommendations of ACSM and AHA for a healthy life are moderate-intensity aerobic physical activity for a minimum of 30 minutes for 5 days per week or vigorous-intensity aerobic physical activity for a minimum of 20 minutes for 3 days per week. 
3. Taking a break of five minutes from work every one hour and stretching legs and walking around will help improve the blood circulation.

4. An alarm can be set or sticky notes can be used to remind yourself about the importance of doing some physical activity every hour.

5. Workstations can be modified to avoid sitting. For example, tall desks can be used for working. It will force us to work by standing, which in turn will help the body burn some energy. Walking while talking over the phone should be made a habit.

6. However, considering the present situation, we should give attention to social distancing.

\section{Conflict of Interest}

None.

\section{References}

1. Ma SX, Zhu Z, Zhang L, Liu XM, Lin YY, Cao ZB. Metabolic Effects of Three Different Activity Bouts during Sitting in Inactive Adults. Med Sci Sports Exerc. 2020;52(4):851-8.

2. Freire YA, Macêdo GAD, Browne RAV, Farias-Junior LF, Bezerra A, Fayh APT, et al. Effect of Breaks in Prolonged Sitting or Low-Volume
High-Intensity Interval Exercise on Markers of Metabolic Syndrome in Adults With Excess Body Fat: A Crossover Trial. J Phys Act Health. 2019;16:727-35. doi:10.1123/jpah.2018-0492.

3. Homer AR, Fenemor SP, Perry TL, Rehrer NJ, Cameron CM, Skeaff CM, et al. Regular activity breaks combined with physical activity improve postprandial plasma triglyceride, nonesterified fatty acid, and insulin responses in healthy, normal weight adults: A randomized crossover trial. J Clin Lipidol. 2017;11(5):1268-79. do1:10.1016/].jacl.2017.06.007.

4. Brocklebank LA, Andrews RC, Page A, Falconer CL, Leary S, Cooper A. The Acute Effects of Breaking Up Seated Office Work With Standing or Light-Intensity Walking on Interstitial Glucose Concentration: A Randomized Crossover Trial. J Phys Act Health. 2017;14(8):617-25. do1:10.1123/jpah.2016-0366.

5. Loh R, Stamatakis E, Folkerts D, Allgrove JE, Moir HJ. Effects of Interrupting Prolonged Sitting with Physical Activity Breaks on Blood Glucose, Insulin and Triacylglycerol Measures: A Systematic Review and Meta-analysis. Sports Med. 2020;50(2):295-30. 10i:10.1007/s40279-(0)9-() 183-w.

\section{Author biography}

Harpreet Kour, Assistant Professor

Cite this article: Kour $\mathrm{H}$. The couch potato syndrome: A major concern in Covid 19 pandemic. Indian J Clin Anat Physiol 2021;8(2):81-82. 